\title{
Human telomerase reverse transcriptase and glucose-regulated protein 78 increase the life span of articular chondrocytes and their repair potential
}

\author{
Masato Sato ${ }^{1 *}$, Kazuo Shin-ya², Jeong Ik Lee³, Miya Ishihara ${ }^{4}$, Toshihiro Nagai', Nagatoshi Kaneshiro', \\ Genya Mitani ${ }^{1}$, Hidetoshi Tahara ${ }^{5}$ and Joji Mochida ${ }^{1}$
}

\begin{abstract}
Background: Like all mammalian cells, normal adult chondrocytes have a limited replicative life span, which decreases with age. To facilitate the therapeutic use of chondrocytes from older donors, a method is needed to prolong their life span.

Methods: We transfected chondrocytes with hTERT or GRP78 and cultured them in a 3-dimensional atelocollagen honeycomb-shaped scaffold with a membrane seal. Then, we measured the amount of nuclear DNA and glycosaminoglycans (GAGs) and the expression level of type II collagen as markers of cell proliferation and extracellular matrix formation, respectively, in these cultures. In addition, we allografted this tissue-engineered cartilage into osteochondral defects in old rabbits to assess their repair activity in vivo.

Results: Our results showed different degrees of differentiation in terms of GAG content between chondrocytes from old and young rabbits. Chondrocytes that were cotransfected with hTERT and GRP78 showed higher cellular proliferation and expression of type II collagen than those of nontransfected chondrocytes, regardless of the age of the cartilage donor. In addition, the in vitro growth rates of hTERT- or GRP78-transfected chondrocytes were higher than those of nontransfected chondrocytes, regardless of donor age. In vivo, the tissue-engineered cartilage implants exhibited strong repairing activity, maintained a chondrocyte-specific phenotype, and produced extracellular matrix components.
\end{abstract}

Conclusions: Focal gene delivery to aged articular chondrocytes exhibited strong repairing activity and may be therapeutically useful for articular cartilage regeneration.

\section{Background}

Osteoarthritis (OA), which is one of the most common, debilitating, and costly chronic disorders [1], is characterized by progressive degeneration or destruction of articular cartilage. Since the incidence of OA increases with age, the underlying mechanism of this disease may involve a loss of the capacity of chondrocytes to regenerate with age. In proliferative cells, telomeres from chromosomes gradually became shorter as a result of the DNA replication end problem. To prevent cessation of mitosis and premature cell death, telomerase is a ribonucleoprotein that is an

\footnotetext{
* Correspondence: sato-m@is.icc.u-tokai.ac.jp

'Department of Orthopaedic Surgery, Surgical Science, Tokai University

School of Medicine, 143 Shimokasuya, Isehara, Kanagawa 259-1193, Japan Full list of author information is available at the end of the article
}

enzyme which adds DNA sequence repeats (TTAGGG) to the 3' end of DNA strands in the telomere regions, which are found at the ends of chromosomes [2]. The telomerase allows for replacement of short bits of DNA known as telomeres, which are otherwise shortened when a cell divides via mitosis. In normal circumstances, without the presence of telomerase, if a cell divides recursively, at some point all the progeny will reach their Hayflick limit. With the presence of telomerase, each dividing cell can replace the lost bit of DNA, and any single cell can then divide unbounded. While this unbounded growth property has excited many researchers, caution is warranted in exploiting this property, as exactly this same unbounded growth is a crucial step in enabling cancerous growth. In immortal human tumor cells, the gene for the catalytic subunit of
C Biomed Central

C 2012 Sato et al; licensee BioMed Central Ltd. This is an Open Access article distributed under the terms of the Creative Commons Attribution License (http://creativecommons.org/licenses/by/2.0), which permits unrestricted use, distribution, and reproduction in any medium, provided the original work is properly cited. 
human telomerase reverse transcriptase ( $h T E R T)$ is almost always derepressed [3]. Moreover, $h T E R T$ is not only an oncoprotein [2] but also a regulator of cellular differentiation $[4,5]$.

As a result, immortalized human cells, such as epithelial and fibroblast cells [6] and chondrocytes $[7,8]$, have been used as models of cellular aging. For example, Goldring [7] showed that primary human chondrocytes can be immortalized with retroviral transfection of 4 genes, including simian vacuolating virus 40 large $\mathrm{T}$ antigen and telomerase; however, stable transfection of hTERT in chondrocytes that are cultured in a monolayer allows maintenance of the proliferative capacity but not the chondrocyte phenotype. In contrast, Piera-Velazquez et al. [8] showed that exogenous expression of $h T E R T$ in chondrocytes that are cultured on polyhydroxyethylmethacrylate coated dishes increases their life span and maintains their chondrocyte phenotype. Thus, hTERT may extend the life span of chondrocytes.

Glucose-regulated protein 78 (GRP78) is a molecular chaperone in the endoplasmic reticulum (ER) that is induced by ER stress and prevents cell death as a result of homeostatic imbalance in the ER [9]. Although overexpression of GRP78 can limit the damage from ER stress in normal tissues and organs, the natural induction of GRP78 in neoplastic cells also may promote cancer progression and drug resistance [10]. Since GRP78 also is involved in the pathology of neurological diseases, such as Alzheimer's disease [11] and Parkinson's disease [12], GRP78 may have therapeutic cytoprotective effects to limit ER stress.

To determine whether $h T E R T$ and GRP78 can prolong the life span of chondrocytes and stimulate cartilage regeneration, we transfected rabbit articular chondrocytes with these genes and redifferentiated chondrocytes in a 3-dimensional atelocollagen honeycomb-shaped scaffold with a membrane seal (ACHMS scaffold) [13]. We used this type of scaffold because it is biodegradable, supports the growth of high-density cell cultures, and maintains the phenotype of articular chondrocytes [14-16]. In addition, to investigate the clinical relevance of our model to OA, we investigated whether the effects of gene transfection depend on the age of the cartilage by analyzing the proliferation, gross morphology, cellular content of DNA and proteoglycans, and gene expression level of type II collagen in the transfected chondrocytes.

\section{Methods}

\section{Preparation of chondrocytes}

All animal experiments in this study approved by Research Support and Intellectual Property of the University of Tokyo were performed in accordance with their institutional guidelines for the care and use of laboratory animals.
Chondrocytes were prepared as described previously [14]. Briefly, articular cartilage tissue specimens were collected from the knee and shoulder joints of 4 young male (4 weeks old, $1 \mathrm{~kg}$ ) and 8 old female (4 years old, $4.5 \mathrm{~kg}$ ) Japanese white rabbits (Tokyo Laboratory Animals Science Co., Ltd., Tokyo, Japan). Each rabbit specimen was soaked and stored separately in basal medium (BM) containing Dulbecco's modified Eagle's medium (DMEM)/F12 (Gibco; Invitrogen, Carlsbad, CA, USA) supplemented with $10 \%$ heat-inactivated fetal bovine serum (FBS) (Gibco), $50 \mu \mathrm{g} \cdot \mathrm{mL}^{-1}$ ascorbic acid (Wako Pure Chemical Industries, Osaka, Japan), and $1 \%$ Fungizone $^{\circledR}$ antibioticantimycotic solution $\left(10,000 \mathrm{U} \cdot \mathrm{mL}^{-1}\right.$ penicillin G, $10 \mathrm{mg} \cdot \mathrm{mL}^{-1}$ streptomycin sulfate, and $25 \mu \mathrm{g} \cdot \mathrm{mL}^{-1}$ amphotericin B; Gibco). When needed, cartilage samples were chopped into small pieces, and then digested for $1 \mathrm{~h}$ in DMEM/F12 containing 0.4\% pronase E (Kaken Pharmaceutical, Tokyo, Japan), followed by digestion for $3 \mathrm{~h}$ at $37^{\circ} \mathrm{C}$ in DMEM/F12 containing $0.016 \%$ collagenase P (Roche Diagnostics, Mannheim, Germany). Subsequently, the digested samples were filtered with a cell strainer (BD Falcon $^{\mathrm{TM}}$; BD Bioscience, Bedford, MA, USA) with a $100 \mu \mathrm{m}$ pore size and the isolated cells were rinsed twice with chilled Dulbecco's calcium- and magnesium-free, phosphate-buffered saline (PBS) (Dainippon Pharmaceutical, Osaka, Japan). The number of viable chondrocytes was counted by using a Burker-Turk hemocytometer (Erma, Tokyo, Japan) with Trypan blue staining. Finally, the chondrocytes were seeded in $500 \mathrm{~cm}^{2}$ square dishes (245 mm $\times 245 \mathrm{~mm}$; Corning, Corning, NY, USA) at a density of 10,000 cells $\cdot \mathrm{cm}^{-2}$ and cultured in BM with $10 \%$ FBS at $37^{\circ} \mathrm{C}$ in an incubator with $5 \% \mathrm{CO}_{2}$.

\section{Retroviral transfection}

Retroviral transfection of cultured chondrocytes was performed as described previously $[17,18]$ with some modifications. First, DH5 $\alpha$ Escherichia coli cells (from Hiroshima University Graduate School of Biomedical Sciences) were cultured overnight in lysogeny broth (LB) media [19] at $37^{\circ} \mathrm{C}$. Subsequently, these cells were transfected with phTERT-MSCV and pGRP78-MSCV plasmids to produce amphotropic viruses. The plasmids were amplified and purified by using an EndoFree Plasmid Maxi Kit (Qiagen, Tokyo, Japan). In addition, the sequence of all constructs was verified by DNA sequencing.

Next, these plasmids were used to produce retroviral constructs by using 2 different protocols. To produce the $h T E R T$ retroviral construct, full-length $h T E R T$ cDNA was polymerase chain reaction (PCR) amplified, and then cloned into the pMSCV-puro retroviral vector (Clontech, Mountain View, CA, USA). Subsequently, the cloned vector was transfected into the Retropack PT67 (Clontech) packaging cell line and the transfected cells were selected with puromycin $\left(1.8 \mu \mathrm{g} \cdot \mathrm{mL}^{-1}\right)$ (Sigma 
Aldrich, St. Louis, MO, USA) after $48 \mathrm{~h}$. Two weeks after transfection, the surviving cells were trypsinized and allowed to continue to grow for up to $100 \mathrm{~d}$. The culture supernatant from this cell line was collected and $0.45-\mu \mathrm{m}$ filtered, and then polybrene $\left(8 \mu \mathrm{g} \cdot \mathrm{mL}^{-1}\right)$ was added prior to transducing $h T E R T$ into young rabbit (YRA) and old rabbit (ORA) chondrocyte cultures.

Chondrocytes were cultured and plated $24 \mathrm{~h}$ before viral infection. Then, the packaged retrovirus was added to the culture media and incubated at $37^{\circ} \mathrm{C}$ in an incubator with $5 \% \mathrm{CO}_{2}$. The infected cells were selected with $0.5 \mu \mathrm{g} \cdot \mathrm{mL}^{-1}$ of puromycin (Sigma Chemical) for 7-10 d prior to subsequent experiments.

To produce the GRP78 retroviral construct, full-length GRP78 cDNA was PCR amplified, and then inserted into the mouse stem cell virus (MSCV) packaging vector by using the Retrovirus Packaging Kit Ampho (TaKaRa Biotechnology, Shiga City, Japan) [20]. To produce GRP78-expressing retroviruses, $293 \mathrm{~T}$ cells (CRL$11268^{\mathrm{TM}}$, ATCC, Manassas, VA, USA) were seeded and maintained on $6-\mathrm{cm}$ dishes at a density of 400,000 cells $\mathrm{cm}^{-2}$ in DMEM containing 10\% FBS for $24 \mathrm{~h}$ prior to transfection. Then, the culture medium was changed to the same medium. Subsequently, the $293 \mathrm{~T}$ cells were co-transfected with pGP (gag-pol) and pE-ampho (env) (TaKaRa Biotechnology) by using calcium phosphate transfection. Transfected cells were selected with 400 $\mu \mathrm{g} \cdot \mathrm{mL}^{-1}$ of hygromycin (Calbiochem, La Jolla, CA, USA) and $50 \mu \mathrm{g}$ of mycophenolic acid (Sigma Aldrich). After $48 \mathrm{~h}$, the culture medium, which contained the recombinant retroviruses, was $0.45-\mu \mathrm{m}$ filtered, and then mixed with DMEM to infect YRA and ORA chondrocyte cultures.

\section{Chondrocyte proliferation}

Chondrocyte proliferation was measured by counting cell numbers at $100 \%$ confluence in serial passages. Briefly, nontransfected or hTERT/GRP78-transfected YRA and ORA chondrocytes, which were passaged once every $7-10 \mathrm{~d}$, were detached by using $0.05 \%$ trypsin/ ethylenediaminetetraacetic acid (EDTA; Gibco) for 20$30 \mathrm{~min}$ at $37^{\circ} \mathrm{C}$ and washed 3 times with PBS. An aliquot of the detached cells was used to count the mean number of cells from 6 dishes by using a Burker-Turk hemocytometer (Erma) with Trypan blue staining. The remaining cells were replated at a density of $5 \times 10^{3}$ cells.well ${ }^{-1}$.

Cell proliferation was expressed as the population doubling level (PDL). The PDL was calculated from logphase growth curves by using the equation: $\mathrm{PDL}=\log _{10}$ $\left(\mathrm{N} / \mathrm{N}_{0}\right) \times 3.33$, where $\mathrm{N}_{0}$ and $\mathrm{N}$ are the number of cells at the beginning and end of each experiment, respectively [21].

\section{Preparation of the atelocollagen honeycomb-shaped} scaffold with a membrane seal and 3-dimensional culture of chondrocytes

The ACHMS scaffold was prepared as described previously [13] by Koken (Tokyo, Japan). Briefly, nontransfected and $h T E R T / G R P 78$-transfected ORA chondrocytes were passaged twice, and then seeded at a density of $2 \times$ $10^{6}$ cells.scaffold ${ }^{-1}$ into a round ACHMS scaffold (diameter, $6 \mathrm{~mm}$; thickness, $2 \mathrm{~mm}$; average pore size, $200 \mu \mathrm{m}$ ) $[13,14,22,23]$ in 48 -well plates (Sumitomo Bakelite, Tokyo, Japan) by centrifuging at $45 \mathrm{~g}$ for $5 \mathrm{~min}$. Then, these cellseeded scaffolds were cultured in BM supplemented with $10 \% \mathrm{FBS}$ at $37^{\circ} \mathrm{C}$ in an incubator with $5 \% \mathrm{CO}_{2}$ and $100 \%$ relative humidity for $14 \mathrm{~d}$. These cultured chondrocytes were frozen in liquid nitrogen until needed for biochemical analyses and transplantation into an in vivo model of articular cartilage defects.

\section{Measurement of DNA and glycosaminoglycans}

The amount of DNA in the cultured ORA chondrocytes, which was used as a marker of cell proliferation, was measured by digesting cell-seeded scaffolds with papain, and then using a fluorimetric assay, as described previously [24]. Briefly, $15 \mu \mathrm{L}$ of a papain digest was mixed with $300 \mu \mathrm{L}$ of Hoechst 33258 solution (Polyscience, Warrington, PA, USA), and then a Titertek Multiscan Spectrofluorometer (Lab Systems, Helsinki, Finland) was used to measure the emission and excitation spectra at $456 \mathrm{~nm}$ and $365 \mathrm{~nm}$, respectively. DNA concentrations were calculated from a standard curve of calf thymus DNA (Sigma).

The amount of glycosaminoglycans (GAGs) in the cultured chondrocytes, which was used as a marker of extracellular matrix (ECM) formation, was quantified by using 1,9-dimethylmethylene blue, as described previously [25]. Briefly, samples $(140 \mu \mathrm{L})$ of each chondrocyte culture were mixed gently with an equal volume of 1,9-dimethylmethylene blue solution in a 96-well microtiter plate, and then the absorbance at $530 \mathrm{~nm}$ was measured with a Titertec multiscan spectrophotometer (Labsystem, Helsinki, Finland). The amount of GAGs was calculated from the absorbance values by using a standard curve of 0.625 $20 \mu \mathrm{g} \cdot \mathrm{mL}^{-1}$ shark chondroitin sulfate C (Seikagaku Kogyo Co, Tokyo, Japan).

\section{Type II collagen mRNA expression}

Frozen 3-dimensional cultures of ORA chondrocytes were pulverized with a Cryo-Press (Microtec Nition, Chiba, Japan) in liquid nitrogen. All oligonucleotide primer sets were designed on the basis of published mRNA sequences. The expected amplicon lengths ranged from 70 to $200 \mathrm{bp}$. Cloning of the entire coding region of type 2 collagen was performed by 5'- and 3'-rapid amplification of cDNA ends 
using the following oligonucleotide primers: forward (5'AACACTGCCAACGTCCAGAT-3'), reverse (5'-CTGC AGCACGGTATAGGTGA-3'). Real-time PCR was performed in a SmartCycler system (Cepheid, Sunnyvale, CA) with SYBR Green PCR Master Mix (Applied Biosystems, Foster City, CA) with $1 \mu \mathrm{L}$ of cDNA template in a final volume of $25 \mu \mathrm{L}$. Amplification of cDNA was performed according to the following conditions: $95^{\circ} \mathrm{C}$ for $15 \mathrm{~s}$ and $60^{\circ} \mathrm{C}$ for $60 \mathrm{~s}$ for $35-45$ amplification cycles. Changes in the fluorescence of SYBR Green were monitored after every cycle. Melting curve analysis was performed through a $0.5^{\circ} \mathrm{C} / \mathrm{s}$ increase from 55 to $95^{\circ} \mathrm{C}$ with continuous fluorescence readings at the end of the cycles to ensure that single PCR products were obtained. All reactions were repeated in six separate PCR runs using RNA isolated from four sets of human samples. The results were evaluated by using SmartCycler software (Cepheid). Glyceraldehyde-3-phosphate dehydrogenase (GAPDH) primers were used to normalize the samples. To monitor crossover contaminations of PCR, RNase-free water (Qiagen, Valencia, CA) was used in the RNA extraction and as a negative control. To ensure the quality of data, a negative control was always included in each run.

\section{Implantation of tissue-engineered cartilage produced from transfected aged chondrocytes}

Twenty four old female Japanese white rabbits were divided into 4 groups (control 8w, 16w; hTERT + GRP78 $8 \mathrm{w}, 16 \mathrm{w}$ ) and anesthetized with intramuscular injections of $120 \mathrm{mg}$ of ketamine (Daiichisankyo, Tokyo, Japan) and $9 \mathrm{mg}$ of xylazine (Bayer HealthCare, Leverkusen, Germany). After creating a medial parapatellar incision in both legs, each patella was dislocated laterally and a cylindrical defect (diameter, $5 \mathrm{~mm}$; depth, $3 \mathrm{~mm}$ ) was created on the patellar groove of the femur in both legs by using a biopsy punch (Kai Industries, Seki, Japan) and a low-speed drill (Takagi, Niigata, Japan). The bottom of the subchondral bone also was shaved to a plane until marrow bleeding was observed. Then, ACHMS scaffolds that were seeded with either nontransfected or hTERT/ GRP78-transfected ORA chondrocytes were allografted into these defects without any fixatives, such as fibrin glue. Postoperatively, all animals were allowed to walk freely in their cages without any splints.

\section{Postoperative analyses}

Eight and 16 weeks after implantation, rabbits were killed with an overdose of intravenous anesthesia, and then the distal parts of their femurs were harvested and observed with a light microscope. Subsequently, the femur samples were fixed in $10 \%$ buffered formalin for $7 \mathrm{~d}$. Each specimen was decalcified with 10\% EDTA in distilled water ( $\mathrm{pH}$ 7.4) for 3 weeks, and then embedded in paraffin, cut into 6 - $\mu \mathrm{m}$-thick sagittal sections, deparaffinized, and stained with safranin O (Cartilage Staining Kit, Takara, Shiga, Japan). The histopathology of the OA cartilage samples $(n=24)$ were analyzed according to standard grading and staging of OA cartilage histopathology [26]. The OA score was calculated by the following formula: OA score $=$ most degenerated site in the cartilage (grades 1-6, Table 1) $\times$ area of degeneration (stages 1-4) (Table 2).

Immunohistochemical staining for type II collagen was performed as described previously [14]. Briefly, after deparaffinization, the sections were pretreated with $0.1 \mathrm{mg} \cdot \mathrm{mL}^{-1}$ of actinase E (Kaken Pharmaceutical) in PBS at $37^{\circ} \mathrm{C}$ for $30 \mathrm{~min}$. Then, the sections were incubated with $10 \%$ pig serum at room temperature for $30 \mathrm{~min}$ to reduce nonspecific background staining. These pretreated sections were incubated overnight with $50 \mathrm{mg} \cdot \mathrm{mL}^{-1}$ mouse anti-human type II collagen monoclonal antibody (Daiichi Fine Chemical, Toyama, Japan) in PBS containing $0.1 \%$ bovine serum albumin at $4^{\circ} \mathrm{C}$. Next, the sections were incubated with biotinylated rabbit antimouse immunoglobulin (1:500 dilution; Dako, Carpinteria, CA, USA) for $30 \mathrm{~min}$ at room temperature, followed by peroxidase-conjugated streptavidin (1:500 dilution; Dako) for $30 \mathrm{~min}$ at room temperature. Finally, the sections were incubated with a solution of $20 \mathrm{mg}$ of diaminobenzidine and $5 \mu \mathrm{L}$ of hydrogen peroxide (30\%) in $100 \mathrm{~mL}$ of PBS for $5 \mathrm{~min}$ at room temperature. Control sections were incubated with PBS without any antibodies and stained in a similar manner. These sections were analyzed by light microscopy.

\section{Statistical analysis}

One-way analysis of variance and Dunn's post hoc test was used to determine statistical significance $(P<0.05)$.

\section{Results}

Establishment of primary cultures of rabbit chondrocytes During the first 3 weeks, YRA, ORA, ORA + hTERT, and ORA + hTERT + GRP78 chondrocytes showed similar growth rates for $10 \mathrm{PDL}$ (Figure 1). Later, ORA + hTERT and ORA + hTERT + GRP78 chondrocytes proliferated more rapidly than the nontransfected chondrocytes. However, YRA + hTERT + GRP78 chondrocytes had the fastest growth rate. In the control groups, YRA chondrocytes proliferated faster than ORA chondrocytes during the entire observation period, but their growth rate gradually decreased until they ceased at about $40 \mathrm{~d}$ and $60 \mathrm{~d}$ after the initiation of culture, respectively. Unlike control cells, which stopped proliferating after 10-20 PDL, ORA $+h T E R T$ and YRA + $h T E R T$ cells continued proliferating for about 35 and 50 PDL, respectively. These results showed that $h T E R T$ and GRP78 increase the growth rate of transfected cells approximately 3 -fold compared with nontransfected cells. 
Table 1 OA cartilage histopathology grade assessment; grading methodology

\begin{tabular}{|c|c|}
\hline Grade (key feature) & Associated criteria (tissue reaction) \\
\hline Grade 1: surface intact & $\begin{array}{l}\text { Matrix: superficial zone intact, oedema and/or superficial fibrillation (abrasion), focal superficial matrix condensation } \\
\text { Cells: death, proliferation (clusters), hypertrophy, superficial zone Reaction must be more than superficial fibrillation only }\end{array}$ \\
\hline $\begin{array}{l}\text { Grade 2: surface } \\
\text { discontinuity }\end{array}$ & $\begin{array}{l}\text { As above } \\
+ \text { Matrix discontinuity at superficial zone (deep fibrillation) } \\
\pm \text { Cationic stain matrix depletion (Safranin O or Toluidine Blue) upper } 1 / 3 \text { of cartilage } \\
\pm \text { Focal perichondronal increased stain (mid zone) } \\
\pm \text { Disorientation of chondron columns } \\
\text { Cells: death, proliferation (clusters), hypertrophy }\end{array}$ \\
\hline $\begin{array}{l}\text { Grade 3: vertical fissures } \\
\text { (clefts) }\end{array}$ & $\begin{array}{c}\text { As above } \\
\text { Matrix vertical fissures into mid zone, branched fissures } \\
\pm \text { Cationic stain depletion (Safranin O or Toluidine Blue) into lower } 2 / 3 \text { of cartilage (deep zone) } \\
\pm \text { New collagen formation (polarized light microscopy, Picro Sirius Red stain) } \\
\text { Cells: death, regeneration (clusters), hypertrophy, cartilage domains adjacent to fissures }\end{array}$ \\
\hline Grade 4: erosion & $\begin{array}{c}\text { Cartilage matrix loss: delamination of superficial layer, mid layer cyst formation } \\
\text { Excavation: matrix loss superficial layer and mid zone }\end{array}$ \\
\hline Grade 5: denudation & $\begin{array}{l}\text { Surface: sclerotic bone or reparative tissue including fibrocartilage within denuded surface. Microfracture with repair } \\
\qquad \text { limited to bone surface }\end{array}$ \\
\hline Grade 6: deformation & $\begin{array}{l}\text { Bone remodelling (more than osteophyte formation only). Includes: microfracturewith fibrocartilaginous and osseous } \\
\text { repair extending above the previous surface }\end{array}$ \\
\hline
\end{tabular}

Grade $=$ depth progression into cartilage

\section{Characteristics of the 3-dimensional cultures of chondrocytes}

The ACHMS scaffold supported a high density of ORA chondrocytes $\left(2 \times 10^{6}\right.$ cells $\left.\cdot \mathrm{cm}^{-2}\right)$ without any leakage of cells. During the 2-week culture, the chondrocytes in the scaffold retained their normal spherical shape (data not shown) and the resulting tissue-engineered cartilage maintained its shape and size in the ACHMS scaffold. The scaffolds were elastic and did not deform during culturing or collapse when handled with forceps.

Figure 2 shows macroscopic images of the cell-seeded scaffolds after culturing for $14 \mathrm{~d}$. The scaffold that was seeded with $h T E R T / G R P 78$-transfected ORA chondrocytes had the highest cell density. In addition, the spaces between the atelocollagen matrix were filled and not visible along the edge of the ACHMS scaffold, which indicated that chondrocytes had proliferated throughout the scaffold during the cultivation period. In the scaffolds that were seeded with control cells, cell growth was sparse, and as a result, the spaces between the atelocollagen matrix remained mostly empty.

\section{Glycosaminoglycan content of cell-seeded scaffolds}

On day 14, the amount of GAG in cell-seeded scaffolds differed significantly between each group (Figure 3). Specifically, the total GAG content of scaffolds that were seeded with $h T E R T / G R P 78$-transfected ORA chondrocytes was higher than those that were seeded with GRP78- or $h T E R T$-transfected cells. In addition, the GAG content of the scaffolds that were seeded with transfected ORA chondrocytes was higher than that in those that were seeded with nontransfected chondrocytes. These results suggested that transfected ORA chondrocytes were able to produce and accumulate significantly higher amounts of extracellular matrix components in the ACHMS scaffold than nontransfected chondrocytes.

Table 2 OA score; semi-quantitative method

\begin{tabular}{|c|c|c|c|c|}
\hline \multirow[t]{2}{*}{ Grade (key feature) } & \multirow[b]{2}{*}{ Stage $1<10 \%$} & \multicolumn{3}{|c|}{ Stage \% Involvement (surface, area, volume) } \\
\hline & & Stage $210-25 \%$ & Stage $325-50 \%$ & Stage $4>50 \%$ \\
\hline $\begin{array}{l}\text { Grade 1(surface } \\
\text { intact) }\end{array}$ & 1 & 2 & 3 & 4 \\
\hline $\begin{array}{l}\text { Grade } 2 \text { (surface } \\
\text { discontinuity) }\end{array}$ & 2 & 4 & 6 & 8 \\
\hline $\begin{array}{l}\text { Grade } 3 \text { (vertical } \\
\text { fissures, clefts) }\end{array}$ & 3 & 6 & 9 & 12 \\
\hline Grade 4 (erosion) & 4 & 8 & 12 & 16 \\
\hline Grade 5(denudation) & 5 & 10 & 15 & 20 \\
\hline Grade 6(deformation) & 6 & 12 & 18 & 24 \\
\hline
\end{tabular}

Score $=$ grade $\times$ stage 


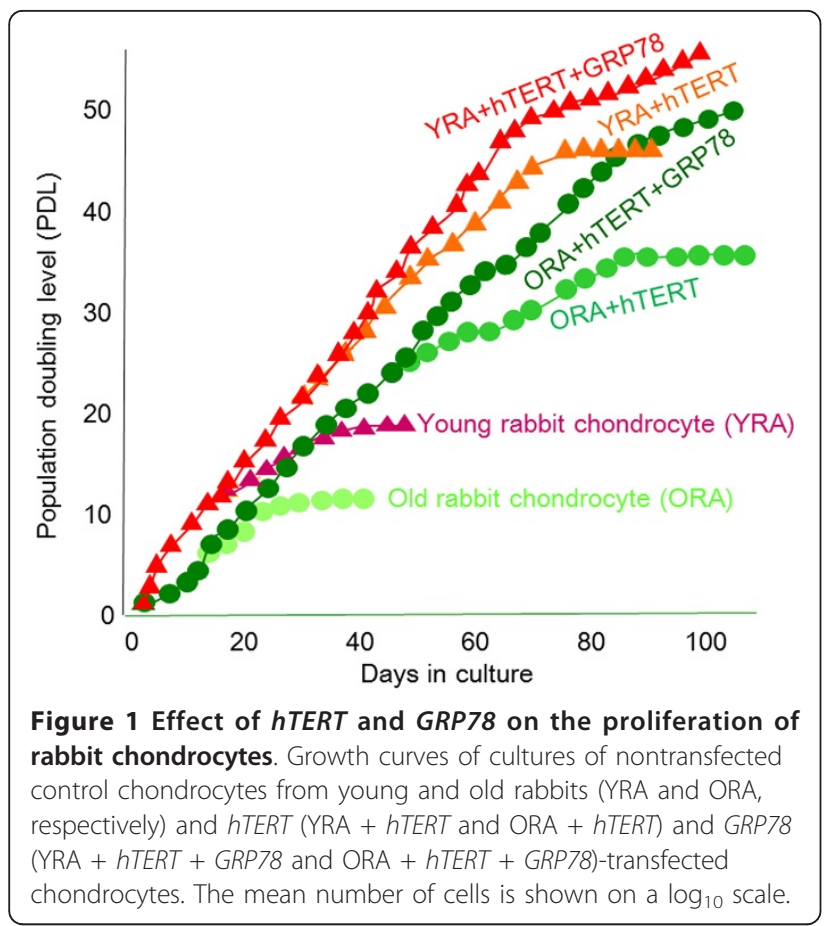

Type II collagen mRNA expression

As shown in Figure 4, the mRNA expression of type II collagen was observed in ORA, regardless of different
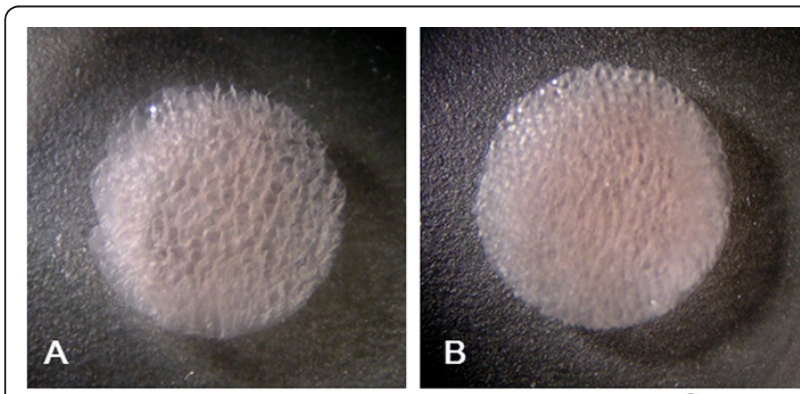

Control

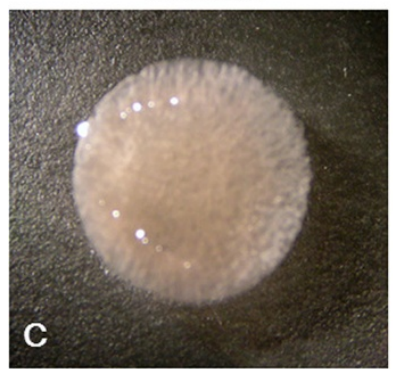

hTERT +

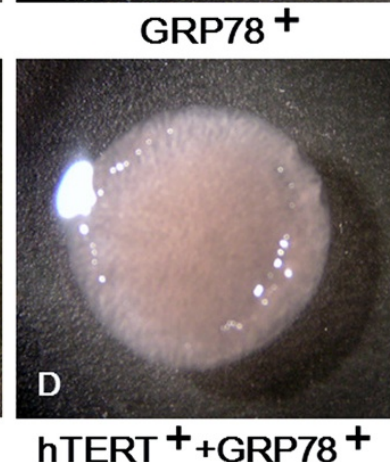

Figure 2 Macroscopic images of the cell-scaffold complex after 14 days of culture. Atelocollagen honeycomb-shaped scaffold with a membrane seal (ACHMS) scaffold complex seeded with nontransfected (A), GRP78-transfected (B), hTERT-transfected (C), or hTERT- and GRP78-transfected (D) ORA chondrocytes. Scale bar $=1.0$ $\mathrm{mm}$.

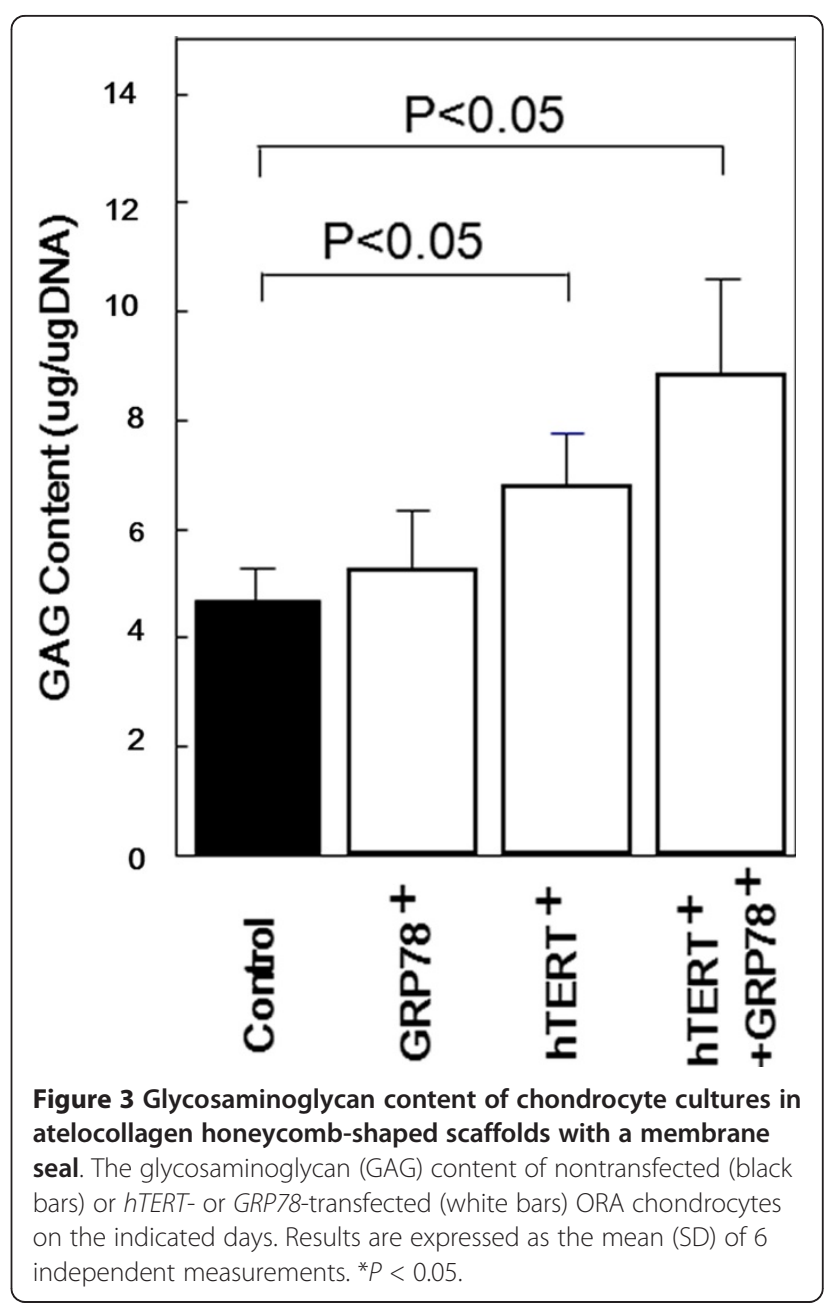

gene transfection. Profiles of control, GRP78 $8^{+}, h T E R T^{+}$, and $h T E R T^{+} / G R P 78^{+}$cells were prepared to investigate expression of type II collagen. The mRNA expressions of $G R P 78^{+}, h T E R T^{+}$, and $h T E R T^{+} / G R P 78^{+}$cells were significantly higher than that in control of non-transfective ORA. Chondrocytes are known to readily dedifferenciate in 2-dimensional culture. However, in this study, we used the primary culture of chondrocytes so that these chondrocytes retain their phenotype, which can be confirmed from type II collagen expression.

\section{Macroscopic appearance of repaired osteochondral defects}

The surgical implantation of tissue-engineered cartilage into osteochondral defects in the old rabbits was uneventful, and upon waking, all rabbits immediately resumed normal cage activity. At the time that they were killed, all rabbits exhibited unlimited passive range of motion in the knee joint.

Indeed, the osteochondral defects in old rabbits that were treated with tissue-engineered cartilage that was 


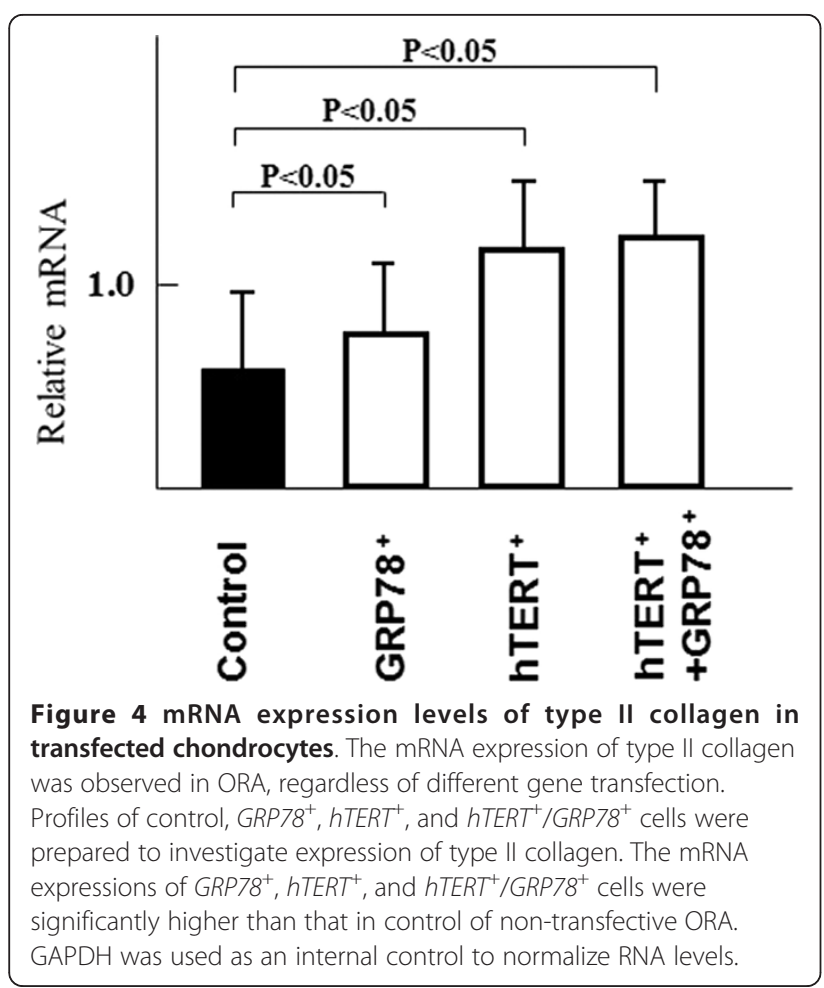

grown from $h T E R T$ - and GRP78-transfected ORA chondrocytes were filled with smooth tissue that resembled hyaline cartilage 16 weeks after surgery (Figure 5E) unlike the tissue-engineered cartilage that was grown from nontransfected ORA chondrocytes, which remained empty or were covered by fibrous tissue (Figure 5B). Although the control tissue-engineered cartilage showed some tissue repair along the borders of the defect, the color of the tissue was slightly different from that of the surrounding normal cartilage (Figure 5A, B).

\section{Histological analysis of repaired osteochondral defects}

No signs of arthritis, such as cartilage erosion or severe synovial proliferation, were observed in any surgically treated knee. In rabbits that were implanted with tissueengineered cartilage grown from $h T E R T$ - and GRP78transfected ORA chondrocytes, the immunohistochemical staining for type II collagen in the extracellular matrix in the scaffold was more intense and covered a larger area (Figure 5F) than those that were implanted with scaffolds that were grown from nontransfected ORA chondrocytes (Figure 5C). In addition, the tissue-engineered cartilage that was grown from transfected ORA chondrocytes was smooth and displayed good bonding with the host cartilage on both sides. In contrast, the tissue-engineered cartilage that was grown from nontransfected ORA chondrocytes had an irregular surface and was thinner than that grown from $h T E R T$ - and GRP78transfected chondrocytes (Figure 5C).

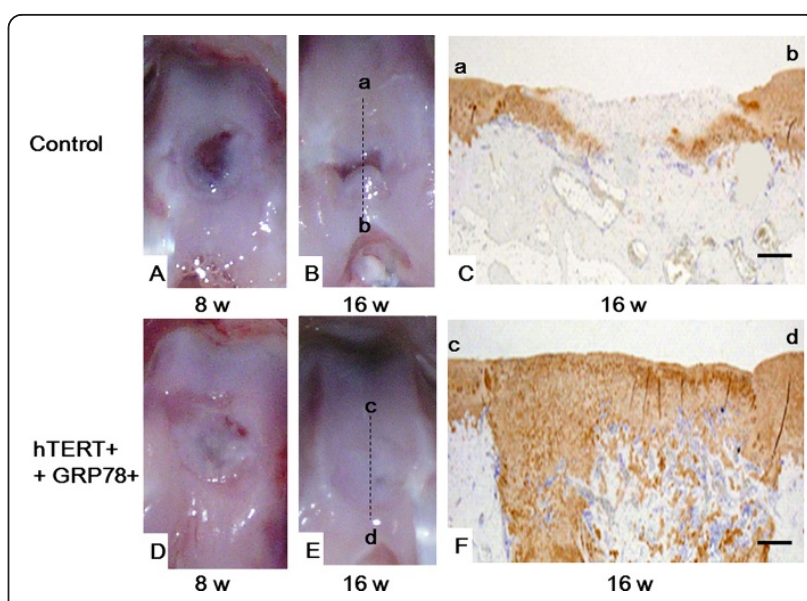

Figure 5 Macroscopic and immunostaining of regenerated cartilage after implantation. Postoperative appearance of repaired osteochondral defects in old rabbits implanted with scaffolds seeded with either nontransfected (top panels) or hTERT- and GRP78-transfected ORA chondrocytes (bottom panels) either 8 (A, D) or $16(B, E)$ weeks after surgery. Immunostaining of type II collagen in tissue sections from rabbits implanted with scaffolds seeded with nontransfected (C) or hTERT- and GRP78-transfected (F) ORA chondrocytes. Each micrograph is representative of 8 tissue samples. Scale bar $=1.0 \mathrm{~mm}$.

As shown in Figure 6, the average OA scores were as follows: control 8w, 11.2 (2.5); 16w, 16.0 (3.2); hTERT + GRP78 8w, 17.3 (3.5); 16w, 21.00 (2.85). Statistically significant differences $(\mathrm{P}<0.05)$ were observed between the transfected and nontransfected groups that were observed for the same period of time after implantation.

\section{Discussion}

Aging is the most important risk factor for both the initiation and progression of degenerative cartilage diseases. Osteoarthritic cartilage degeneration may be due to the loss of viable chondrocytes due to apoptosis or physical stress. This degeneration is likely to be closely related to age-related changes, since aging chondrocytes and articular cartilage matrix undergo senescence-like changes, which increase the susceptibility of cells to degenerative processes and environmental or physiological stresses [27]. As a result, chondrocytes from osteoarthritic patients might progress toward senescence more rapidly than those from normal individuals.

Aging chondrocytes also have important therapeutic ramifications. Recently, the treatment of articular cartilage defects have improved with the introduction of advanced tissue engineering techniques for autologous chondrocyte implantation (ACI) [28]. ACI requires cell expansion in culture to provide sufficient amounts of chondrocytes for reimplantation. However, like all mammalian cells, normal adult chondrocytes have a limited mitotic potential and eventually enter a state of senescence [29]. Moreover, the 


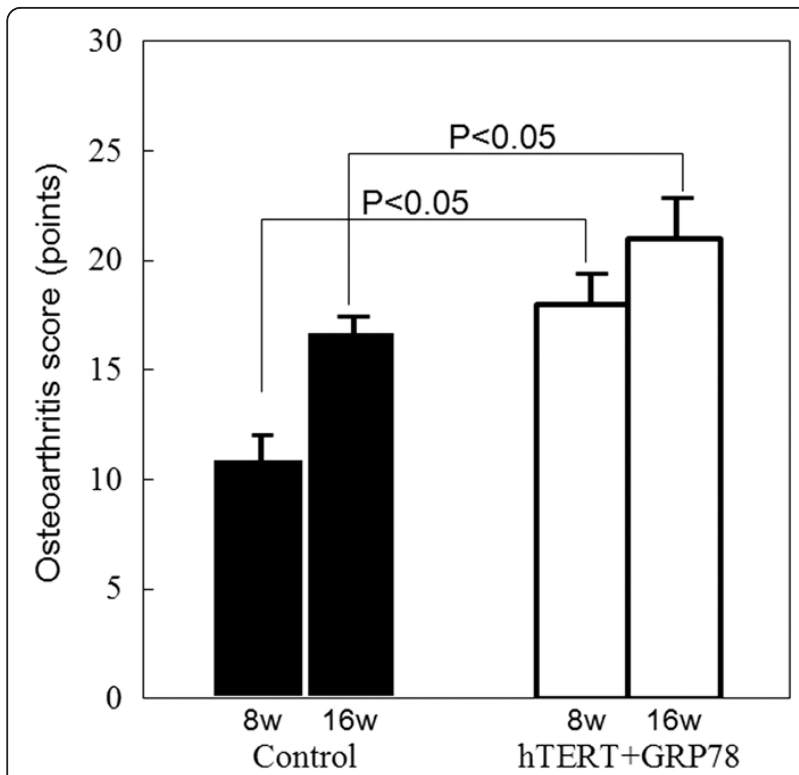

Figure 6 Osteoarthritis score. The histopathology of the OA cartilage samples from all 4 groups $(n=24)$ were analyzed according to standard grading and staging of OA cartilage histopathology. OA scores were calculated by using the following formula: OA score = most degenerated site in the cartilage (grades 1-6, Table 1) $\times$ area of degeneration (stages 1-4) (Table 2). Error bars indicate the standard deviation of each group. Statistically significant differences were observed between the control and hTERT + GRP78 groups 8 and 16 weeks after transplantation.

replicative life span of primary cells in culture are affected by the age of the donor, such that cells from older donors have a shorter life spans than those from younger donors [30]. For example, in monolayer cultures of aged human chondrocytes, serial passages rapidly results in loss of phenotypic stability and proliferative capacity [7]. Thus, to facilitate the therapeutic use of chondrocytes from older donors, a method is needed to prolong their replicative life span.

One possible method is transfection of $h T E R T$, which can immortalize or prolong the life span of various human cells, such as muscle satellite cells [31,32], myoblasts $[33,34]$, fibroblasts [6], and chondrocytes [7,8]. Since most immortalized cells maintain their phenotype and state of differentiation, $h T E R T$-transfected cells are considered potential therapies for small-cell lung cancer [35] and for postnatal neovascularization in severe ischemic disease [36]. However, since chondrocytes uniquely maintain their phenotypes in 3-dimensional cultures [37], it is not known whether $h T E R T$-immortalized chondrocytes maintain their state of differentiation.

Due to the aforementioned issues, in most cartilage tissue engineering studies, donor chondrocytes are usually from young animals. Our study is the first report that transfection of $h T E R T$ and GRP78 can increase the replicative life span and therapeutic potential of tissue- engineered cartilage that is produced from ORA chondrocytes, which have a limited regenerative capacity. In addition, we used an ACHMS scaffold to maintain the phenotype of transfected chondrocytes, as indicated by the production of GAGs and type II collagen (Figures 3 and 4). These results are consistent with the findings of Piera-Velazquez et al. [8].

In this study, we overcame the limited lifespan of ORA chondrocytes by transfection with $h T E R T$ and increased their growth rate up to 3 -fold by cotransfection with GRP78 (Figure 1). Specifically, hTERT/GRP78-transfected ORA chondrocytes grew at a constant rate for more than 20 PDL, whereas nontransfected chondrocytes stopped dividing after much fewer PDL. However, we were not able to completely immortalize chondrocytes, even those from young rabbits (PDL $<50)$. Although the additional transfection of SV40-TAg or mutant Ras could immortalize these cells, we did not choose this option because the transfected cells may have become cancerous. As a result, we focused on the phenotypic stability of GRP78 and hTERT.

hTERT is a candidate gene for gene therapy of muscular dystrophy [31-34]. In contrast, GRP78 may have therapeutic applications for neuropathological conditions, such as Alzheimer's disease, because it protects cells from ER stress [11,38-40]. ER stress can alter protein synthesis in cells [41]. One mechanism by which ER stress promotes apoptosis in cells is by driving the accumulation of structurally abnormal proteins [42], which are ordinarily repaired by ER chaperones to prevent agerelated cell death. GRP78 is an example of a chaperone protein that regulates protein folding in the ER and thus contributes to cell survival [43]. Since the increase in the expression of GRP78 during cell culture may help protect cells from ER stress, overexpression of GRP78 also may protect cultured chondrocytes independent of hTERT.

Due to a lack of cages for mutant rabbits, we were not able to perform animal transplantation experiments with chondrocytes that were transfected with $h T E R T$ or GRP78 alone. However, we believe that our in vitro and in vivo results from chondrocytes that were transfected with both $h T E R T$ and GRP78 are sufficient to support our conclusions. In the future, we plan to perform more animal experiments to elucidate the effects of GRP78.

In conclusion, our results showed that tissue-engineered cartilage that was grown from implanted in vivo with hTERT- and GRP78-transfected ORA chondrocytes in ACHMS scaffolds can repair articular cartilage defects in vivo (Figure 5D, E, F). The $h T E R T$ and GRP78-transfected ORA exhibited proliferative and differentiation activity in articular cartilage defects, resulting in the formation of hyaline cartilage. This study also shows that ORA chondrocytes potentially produce hyaline cartilage after genetic treatment, similar to chondrocytes from young animals. 
However, the mechanical strength of regenerated articular cartilage in large animals (i.e., sheep or pigs) needs to be investigated.

\begin{abstract}
Abbreviations
hTERT: Human telomerase reverse transcriptase; GRP78: Glucose-regulated protein 78; ER: Endoplasmic reticulum; ACHMS scaffold: Atelocollagen honeycomb-shaped scaffold with a membrane seal; OA: Osteoarthritis; BM: Basal medium; DMEM: Dulbecco's modified Eagle's medium; FBS: Fetal bovine serum; YRA: Young rabbit; ORA: Old rabbit; PDL: Population doubling level; RT-PCR: Reverse transcriptase-polymerase chain reaction; GAPDH: Gylceraldehyde-3-phosphate dehydrogenase; ACl: Autologous chondrocyte implantation; ECM: Extracellular matrix.
\end{abstract}

\section{Acknowledgements}

This work was supported by the Takeda Science Foundation, Grant of the New Energy and Industrial Technology Development Organization, and High-Tech Research Center Project 2004 for Private University. The funders had no role in study design, data collection and analysis, decision to publish, or preparation of the manuscript.

\section{Author details}

'Department of Orthopaedic Surgery, Surgical Science, Tokai University School of Medicine, 143 Shimokasuya, Isehara, Kanagawa 259-1193, Japan. ${ }^{2}$ Biomedicinal Information Research Center, National Institute of Advanced Industrial Science and Technology (AIST), 2-42 Aomi, Koto-ku, Tokyo 1350064, Japan. ${ }^{3}$ Department of Biomedical Science \& Technology, Institute of Biomedical Science \& Technology (IBST), Konkuk University, 1 Hwang-dong, Gwangjin-gu, Seoul 143-701, Korea. ${ }^{4}$ Department of Medical Engineering, National Defense Medical College, 3-2 Namiki, Tokorozawa, Saitama 3598513, Japan. ${ }^{5}$ Hiroshima University Graduate School of Biomedical Sciences, 1-2-3 Kasumi, Minami-ku, Hiroshima 734-8553, Japan.

\section{Authors' contributions}

MS, KS, MI, and TN conducted the experiments. MS, MI, NK, TK, HT, and GM analyzed the data. JIL performed the statistical analyses. MS, JIL, and JM wrote the manuscript. All authors read and approved the final manuscript.

\section{Competing interests}

The authors declare that they have no competing interests.

Received: 3 November 2011 Accepted: 2 April 2012

Published: 2 April 2012

\section{References}

1. Issa SN, Sharma L: Epidemiology of osteoarthritis: an update. Curr Rheumatol Rep 2006, 8:7-15.

2. Harley CB: Telomerase is not an oncogene. Oncogene 2002, 21:494-502.

3. Meyerson M, Counter CM, Eaton EN, Ellisen LW, Steiner P, Caddle SD, Ziaugra L, Beijersbergen RL, Davidoff MJ, Liu Q, Bacchetti S, Haber DA, Weinberg RA: hEST2, the putative human telomerase catalytic subunit gene, is up-regulated in tumor cells and during immortalization. Cell 1997, 90:785-795.

4. Mattson MP, Fu W, Zhang P: Emerging roles for telomerase in regulating cell differentiation and survival: a neuroscientist's perspective. Mech Ageing Dev 2001, 122:659-671.

5. Liu L, DiGirolamo CM, Navarro PA, Blasco MA, Keefe DL: Telomerase deficiency impairs differentiation of mesenchymal stem cells. Exp Cell Res 2004, 294:1-8.

6. Hahn WC, Counter CM, Lundberg AS, Beijersbergen RL, Brooks MW, Weinberg RA: Creation of human tumour cells with defined genetic elements. Nature 1999, 400:464-468.

7. Goldring MB: Immortalization of human articular chondrocytes for generation of stable, differentiated cell lines. Methods Mol Med 2004, 100:23-36.

8. Piera-Velazquez S, Jimenez SA, Stokes D: Increased life span of human osteoarthritic chondrocytes by exogenous expression of telomerase. Arthritis Rheum 2002, 46:683-693.
9. Reddy RK, Mao C, Baumeister P, Austin RC, Kaufman RJ, Lee AS: Endoplasmic reticulum chaperone protein GRP78 protects cells from apoptosis induced by topoisomerase inhibitors: role of ATP binding site in suppression of caspase-7 activation. J Biol Chem 2003, 278:20915-20924.

10. Lee AS: The glucose-regulated proteins: stress induction and clinical applications. Trends Biochem Sci 2001, 26:504-510.

11. Katayama T, Imaizumi K, Manabe T, Hitomi J, Kudo T, Tohyama M: Induction of neuronal death by ER stress in Alzheimer's disease. J Chem Neuroanat 2004, 28:67-78.

12. Ryu EJ, Harding HP, Angelastro JM, Vitolo OV, Ron D, Greene LA: Endoplasmic reticulum stress and the unfolded protein response in cellular models of Parkinson's disease. J Neurosci 2002, 22:10690-10698.

13. Sato M, Asazuma T, Ishihara M, Kikuchi T, Masuoka K, Ichimura S, Kikuchi M, Kurita A, Fujikawa K: An atelocollagen honeycomb-shaped scaffold with a membrane seal (ACHMS-scaffold) for the culture of annulus fibrosus cells from an intervertebral disc. J Biomed Mater Res A 2003, 64:248-256.

14. Masuoka $K$, Asazuma T, Ishihara M, Sato M, Hattori H, Ishihara M, Yoshihara Y, Matsui T, Takase B, Kikuchi M, Nemoto K: Tissue engineering of articular cartilage using an allograft of cultured chondrocytes in a membrane-sealed atelocollagen honeycomb-shaped scaffold (ACHMS scaffold). J Biomed Mater Res B Appl Biomater 2005, 75:177-184.

15. Ishihara M, Sato M, Sato S, Kikuchi T, Mochida J, Kikuchi M: Usefulness of photoacoustic measurements for evaluation of biomechanical properties of tissue-engineered cartilage. Tissue Eng 2005, 11:1234-1243.

16. Glowacki J, Mizuno S: Collagen scaffolds for tissue engineering. Biopolymers 2008, 89:338-344

17. Pear WS, Nolan GP, Scott ML, Baltimore D: Production of high-titer helperfree retroviruses by transient transfection. Proc Natl Acad Sci USA 1993, 90:8392-8396.

18. Fujita T, Otsuka-Tanaka Y, Tahara H, Ide T, Abiko Y, Mega J: Establishment of immortalized clonal cells derived from periodontal ligament cells by induction of the hTERT gene. J Oral Sci 2005, 47:177-184.

19. Bertani G: Lysogeny at mid-twentieth century: P1, P2, and other experimental systems. J Bacterio/ 2004, 186:595-600.

20. Hawley RG, Lieu FH, Fong AZ, Hawley TS: Versatile retroviral vectors for potential use in gene therapy. Gene Ther 1994, 1:136-138.

21. Cristofalo VJ, Allen RG, Pignolo RJ, Martin BG, Beck JC: Relationship between donor age and the replicative lifespan of human cells in culture: a reevaluation. Proc Natl Acad Sci USA 1998, 95:10614-10619.

22. Itoh $H$, Aso $Y$, Furuse $M$, Noishiki $Y$, Miyata T: A honeycomb collagen carrier for cell culture as a tissue engineering scaffold. Artif Organs 2001, 25:213-217.

23. Hattori H, Sato M, Masuoka K, Ishihara M, Kikuchi T, Matsui T, Takase B, Ishizuka T, Kikuchi M, Fujikawa K, Ishihara M: Osteogenic potential of human adipose tissue-derived stromal cells as an alternative stem cell source. Cells Tissues Organs 2004, 178:2-12.

24. Kim YJ, Sah RL, Doong JY, Grodzinsky AJ: Fluorometric assay of DNA in cartilage explants using Hoechst 33258. Anal Biochem 1988, 174:168-176.

25. Farndale RW, Buttle DJ, Barrett AJ: Improved quantitation and discrimination of sulphated glycosaminoglycans by use of dimethylmethylene blue. Biochim Biophys Acta 1986, 883:173-177.

26. Pritzker KP, Gay S, Jimenez SA, Ostergaard K, Pelletier JP, Revell PA, Salter D, van den Berg WB: Osteoarthritis cartilage histopathology: grading and staging. Osteoarthritis Cartilage 2006, 14:13-29.

27. Aigner T, Rose J, Martin J, Buckwalter J: Aging theories of primary osteoarthritis: from epidemiology to molecular biology. Rejuvenation Res 2004, 7:134-145.

28. Brittberg M, Lindahl A, Nilsson A, Ohlsson C, Isaksson O, Peterson L: Treatment of Deep Cartilage Defects in the Knee with Autologous Chondrocyte Transplantation. N Engl J Med 1994, 331:889-895.

29. Evans $\mathrm{CH}$, Georgescu Hl: Observations on the senescence of cells derived from articular cartilage. Mech Ageing Dev 1983, 22:179-191.

30. Hayflick $L:$ The limited in vitro lifetime of human diploid cell strains. Exp Cell Res 1965, 37:614-636.

31. Cudre-Mauroux C, Occhiodoro T, Konig S, Salmon P, Bernheim L, Trono D: Lentivector-mediated transfer of Bmi-1 and telomerase in muscle satellite cells yields a duchenne myoblast cell line with long-term genotypic and phenotypic stability. Hum Gene Ther 2003, 14:1525-1533.

32. Di Donna S, Renault V, Forestier C, Piron-Hamelin G, Thiesson D, Cooper RN, Ponsot E, Decary S, Amouri R, Hentati F, Butler-Browne GS, Mouly V: 
Regenerative capacity of human satellite cells: the mitotic clock in cell transplantation. Neurol Sci 2000, 21(Suppl 5):S943-S951.

33. Seigneurin-Venin S, Bernard V, Moisset PA, Ouellette MM, Mouly V, Di Donna S, Wright WE, Tremblay JP: Transplantation of normal and DMD myoblasts expressing the telomerase gene in SCID mice. Biochem Biophys Res Commun 2000, 272:362-369.

34. Seigneurin-Venin S, Bernard V, Tremblay JP: Telomerase allows the immortalization of T antigen-positive DMD myoblasts: a new source of cells for gene transfer application. Gene Ther 2000, 7:619-623.

35. Song JS: Adenovirus-mediated suicide SCLC gene therapy using the increased activity of the hTERT promoter by the MMRE and SV40 enhancer. Biosci Biotechnol Biochem 2005, 69:56-62.

36. Murasawa S, Llevadot J, Silver M, Isner JM, Losordo DW, Asahara T: Constitutive human telomerase reverse transcripase expression enhances regenerative properties of endothelial progenitor cells. Circulation 2002, 106:1133-1139.

37. Watt FM: Effect of seeding density on stability of the differentiated phenotype of pig articular chondrocytes in culture. J Cell Sci 1988, 89(Pt 3):373-378.

38. Kudo T, Okumura M, Imaizumi K, Araki W, Morihara T, Tanimukai $H_{\text {, }}$ Kamagata E, Tabuchi N, Kimura R, Kanayama D, Fukumori A, Tagami S, Okochi M, Kubo M, Tanii H, Tohyama M, Tabira T, Takeda M: Altered localization of amyloid precursor protein under endoplasmic reticulum stress. Biochem Biophys Res Commun 2006, 344:525-530.

39. Kudo T, Katayama T, Imaizumi K, Yasuda Y, Yatera M, Okochi M, Tohyama M, Takeda M: The unfolded protein response is involved in the pathology of Alzheimer's disease. Ann N Y Acad Sci 2002, 977:349-355.

40. Yasuda Y, Kudo T, Katayama T, Imaizumi K, Yatera M, Okochi M, Yamamori H, Matsumoto N, Kida T, Fukumori A, Okumura M, Tohyama M, Takeda M: FAD-linked presenilin-1 mutants impede translation regulation under ER stress. Biochem Biophys Res Commun 2002, 296:313-318.

41. Kozutsumi Y, Segal M, Normington K, Gething MJ, Sambrook J: The presence of malfolded proteins in the endoplasmic reticulum signals the induction of glucose-regulated proteins. Nature 1988, 332:462-464.

42. Oyadomari S, Mori M: Roles of CHOP/GADD153 in endoplasmic reticulum stress. Cell Death Differ 2004, 11:381-389.

43. Ni M, Lee AS: ER chaperones in mammalian development and human diseases. FEBS Lett 2007, 581:3641-3651.

\section{Pre-publication history}

The pre-publication history for this paper can be accessed here: http://www.biomedcentral.com/1471-2474/13/51/prepub

doi:10.1186/1471-2474-13-51

Cite this article as: Sato et al:: Human telomerase reverse transcriptase and glucose-regulated protein 78 increase the life span of articular chondrocytes and their repair potential. BMC Musculoskeletal Disorders 2012 13:51.

\section{Submit your next manuscript to BioMed Central and take full advantage of:}

- Convenient online submission

- Thorough peer review

- No space constraints or color figure charges

- Immediate publication on acceptance

- Inclusion in PubMed, CAS, Scopus and Google Scholar

- Research which is freely available for redistribution

Submit your manuscript at www.biomedcentral.com/submit
Biomed Central 